\title{
PERSPECTIVAS SOBRE LA EXISTENCIA \\ EN LA FILOSOFÍA CONTEMPORÁNEA: \\ KIERKEGAARD Y MARKUS GABRIEL ${ }^{1}$
}

\author{
Alejandro Ruiz Zizumbo \\ Universidad Michoacana de San Nicolás de Hidalgo, México
}

\section{Resumen}

Kierkegaard y Markus Gabriel han expuesto el tema de la existencia en épocas y contextos distintos, en ambos autores la categoría se puede considerar un eje subversivo que se opone a las abstracciones racionales y a los intentos de generalizar un modo único de existencia. El propósito del presente estudio es mostrar cómo en cada uno de ellos la categoría ha sido un eje subversivo que ha caracterizado su pensamiento, cuáles han sido algunas de sus influencias y de qué manera han cuestionado la metafísica de los sistemas filosóficos dominantes de su tiempo. En la actualidad el tema no ha quedado agotado y a partir de su noción de existencia intento establecer un diálogo y mostrar cuál es el horizonte de esta categoría en la filosofía contemporánea.

Palabras clave: Existencia, campo de sentido, cientificismo, libertad, desesperación.

\section{Abstract}

Kierkegaard and Markus Gabriel have exposed the issue of existence in different times and contexts, in both authors the category can be considered a subversive axis that opposes rational abstractions and attempts to generalize a unique mode of existence. The purpose of this study is to show how in each of them the category has been a subversive axis that has characterized his thinking and how they have questioned the metaphysics of the dominant philosophical systems of his time. In the present time the topic has not been exhausted and from its notion of existence I try to establish a dialogue and show what is the horizon of this category in contemporary philosophy.

Keywords: Existence, field of sense, scientism, freedom, despair.

${ }^{1}$ Recibido el 30 de abril de 2020; aceptado el 9 de junio de 2020. 


\section{Introducción}

Exponer dos posturas sobre la existencia es el objetivo del presente artículo, la primera es la de Kierkegaard y la segunda es la del filósofo alemán Markus Gabriel. La intención es mostrar cómo estos autores han profundizado en el tema de manera controversial a partir de dicha noción, ambos desde horizontes y tradiciones distintas. No obstante, considero que en cada uno de ellos la categoría ha sido un eje subversivo que ha caracterizado su pensamiento y es allí donde encuentro un posible diálogo entre los dos pensadores porque se oponen a una generalidad y realidad absoluta; dicho de otra manera, a un modo único de existencia. Por lo tanto, al tratar de acercarlos tomo en cuenta que en esta frontera de su pensamiento también sobresalen diferencias considerables, lo que me lleva a no forzar a que encuadren otras de sus categorías. En virtud de esta advertencia, lo que voy a señalar como hilo conductor son algunas características de su noción de existencia y cómo esta objeta en contra de posturas actuales que ven a la existencia y la libertad como epifenómenos.

$\mathrm{Al}$ mismo tiempo que la existencia es el tema que puede permitir un diálogo entre ambos, puede llamar la atención que los autores son de épocas y contextos distintos. Kierkegaard se ubica en la mitad del siglo XIX, sus preocupaciones se enfocaron en el individuo y en señalar que no hay un modo general de existencia; al revisar estas preocupaciones sobresalen los estadios que se distinguen porque en ellos no hay mediación para pasar de uno a otro, sino un salto. Estas son algunas de las características que han hecho que la perspectiva kierkegaardiana sea uno de los referentes críticos y una referencia insoslayable para abordar la existencia como tema filosófico.

Por otro lado, al revisar la noción de existencia en Gabriel como un autor actual se puede constatar el lugar central que la noción ocupa en su pensamiento, su postura pertenece al resurgimiento contemporáneo del realismo filosófico ${ }^{2}$ expuesto en los últimos años. Entre las distintas ideas que articulan su pensamiento destaca el diálogo que establece con la filosofía contemporánea donde incluye a la tradición continental y analítica. Cabe mencionar que ha sido el encuentro entre las dos tradiciones filosóficas el punto que lo llevó a plantear una noción de existencia que converge con lo

${ }^{2}$ En las modalidades que tiene el realismo filosófico contemporáneo hay varios autores y Markus Gabriel es uno de sus representantes. Otros autores relevantes son Mauricio Ferraris, Graham Harman y Quentin Meullassoux. Para profundizar sobre el nuevo realismo se puede consultar Mario T. Ramírez, El nuevo realismo. La filosofía del siglo XXI, Coord. Mario T. Ramírez, México: UMSNH-Siglo XXI, 2016. 
que llama campos de sentido, sin perder de vista que cuando hace referencia a sentido está presente la influencia de la noción de Frege.

\section{La influencia de la filosofía moderna en Kierkegaard y Markus Gabriel}

En este apartado voy a señalar un precedente de la existencia que Kierkegaard conoció en persona en el invierno de 1841 y Gabriel como experto en el idealismo alemán le ha dedicado varios de sus trabajos académicos. La intención es mostrar cuáles han sido algunas de las influencias que han tenido del pensamiento moderno en su noción de existencia y qué recepción ha tenido en su obra, ya que fue en el siglo XIX cuando la categoría de la existencia cobró una importancia particular en las discusiones filosóficas y en cierta medida, al día de hoy sigue abonando en la palestra de los debates contemporáneos, debido a que en la actualidad dentro y fuera de la filosofía se siguen planteando interrogantes sobre qué es la existencia y cómo podemos entender nuestra existencia. Con las preguntas anteriores se puede subrayar que el tema no ha sido agotado y a diferencia de la época premoderna, es en la época moderna donde la categoría empezó a tener una perspectiva contingente en lo humano, siendo Schelling quien la introdujo y desarrolló en su filosofía tardía.

Ahora bien, al tomar en cuenta el pensamiento de Schelling se da la posibilidad de un diálogo, aunque sea efímero entre Kierkegaard y Gabriel, porque estos dos autores han sido conocedores de la filosofía schellingueana y los aportes de esa filosofía han sido un precedente que fue retomado u objetado en algunos puntos de sus obras. En el caso de Kierkegaard, está el antecedente de su único viaje académico fuera de Dinamarca para asistir al curso que Schelling dio en Berlín en el invierno de $1841^{3}$. Con

${ }^{3}$ El encuentro entre Schelling y Kierkegaard ha sido controversial, ya que este episodio quedó ensombrecido por el mismo Kierkegaard, debido a que abandonó el curso antes de que llegara a su fin. No obstante, hay varias lecturas sobre el curso de Berlín y la influencia del pensamiento del Schelling en el pensador danés que sugieren fue clave para la articulación de sus planteamientos existenciales. Algunos de los estudios relevantes en los últimos años son el de Kierkegaard Studies Monograph Series titulado Kierkegaard und Schelling. Frebeit, Angst und Wirklichkeit. Michelle Kosh, Freedom and Reason in Kant, Schelling and Kierkegaard, New York: Oxford University Press, 2006. En español está el estudio titulado "Schelling y Kierkegaard: La génesis de la angustia contemporánea", realizado por Fernando Pérez Borbujo, Francesc Torralba y Jacobo Zabalo el cual se encuentra como introducción a la obra Søren Kierkegaard, Apuntes sobre la Filosofía de la Revelación de F. W. J. Schelling (1841-1842), trad. de Óscar Parcero, Madrid: Trotta, 2014. 
Gabriel destaca que su formación ha sido parecida a la de Schelling, es un conocedor de la historia de la filosofía particularmente del Idealismo Alemán y el trabajo de su tesis doctoral fue sobre Schelling y la mitología 4 . De esta manera, ambos no han sido ajenos al pensamiento schellingueano y a la oposición directa que tuvo hacia el sistema hegeliano.

Asimismo, el pensamiento de Schelling se puede ubicar en varias etapas y al ser un filósofo de longevidad considerable "sobrevivió con mucho a todos los idealistas. Y no sólo a ellos. Prácticamente llegó a vivir tanto como dos de sus más relevantes lectores, Kierkegaard y Schopenhauer" ${ }^{5}$. No obstante, para los propósitos del presente estudio considero que es el periodo de su filosofía tardía el de mayor relevancia, ya que es donde se preocupó por un nuevo modo de hacer filosofía; es decir, por una filosofía que le diera un lugar serio a la existencia, la libertad y la contingencia. A lo largo de esta nueva propuesta filosófica Schelling ubicó cuáles eran los límites de la razón y del proyecto del idealismo, que paradójicamente tiempo atrás había inaugurado. En esta nueva lectura que hizo de la filosofía y de darle prioridad a categorías como la existencia y la libertad no solamente lo llevó hacia las preocupaciones humanas, sino también a ubicar dos filosofías, una negativa que era puramente racional y una positiva que parte de la existencia y de lo imprepensable comprendido como acontecimiento.

Este antecedente del pensamiento moderno fue enmarcado en el siglo XX por Hannah Arendt, dado que en su perspectiva filosófica de la existencia señaló que "tiene una historia de por lo menos ciento cincuenta años. Comenzó con Schelling, el Schelling de los últimos años de su vida y continuó con Kierkegaard" ". Cabe destacar que fue el mismo Gabriel quien subrayó este mismo antecedente de la historia de la filosofía y en su obra Trascendental Ontology, ha ubicado a Schelling como un autor que tuvo un pensamiento revolucionario que influyó en la articulación de los presupuestos del existencialismo ${ }^{7}$. Por lo tanto, en una dirección distinta a la filosofía dominante de su época Schelling expuso categorías como la libertad y la existencia, con ellas se opuso a la filosofía que llamó racional

${ }^{4}$ La tesis doctoral de Markus Gabriel se titula: Der Mensch im MythosUntersuchungen über Ontotheologie, Anthropologie und Selbstbewußtseinsgeschichtein Schellings "Philosophie der Mythologie". Ver la tesis en https://www.degruyter.com/view/product/62160?lang=en 5 José Luis Villacañas, La filosofía del idealismo alemán. Vol. II La hegemonía de Hegel, Madrid: Síntesis, 2001, p. 297

"Hannah Arendt, "La filosofía de la existencia", Tarea, memoria académica no. 1, 1968, p. 48.

${ }^{7}$ Cfr. Markus Gabriel, Trascendental Ontology. Essays in German Idealism, Nueva York: Continuum, 2011, p. 98. 
o negativa. En esta oposición señaló los errores de los sistemas filosóficos precedentes que han dejado fuera categorías como la voluntad, la existencia y la libertad. En el contexto de sus críticas ubicó a Descartes, Spinoza, Kant, Jacobi y Hegel; a todos ellos les objetó que en la perspectiva de sus sistemas "no conocieron otra filosofía más que la racional, capaz de ser solamente negativa" 8

Es probable que la clave para comprender las ideas schellingueanas que abonaron a la filosofía de la existencia remitan a la distinción que hizo entre la filosofía positiva y negativa, ideas que fueron desarrolladas en " $\mathrm{La}$ filosofía de la revelación, la cual resume la totalidad de los intereses filosóficos del último Schelling y los expone de una manera plenamente madura" . Por consiguiente, una de las objeciones que se encuentran en el Schelling tardío hacia la filosofía negativa apuntó a que "no se ocupa de lo realmente existente" 10 por ser conceptual y sistemática; es decir, opera con conceptos y trata de encontrar definiciones objetivas de todo lo que estudia. Schelling se dio cuenta de esta manera de proceder y como ejemplo señaló la filosofía hegeliana por ser la que dominaba en ese momento y ser un referente claro de una filosofía negativa, debido a que se limitó a puntualizar los contenidos predicativos y no la existencia real y actual.

En contraste, la filosofía que Schelling llamó positiva apuntó a dar respuestas a problemáticas que la filosofía racional o negativa no pudo dar a partir de conceptualizaciones. Lo que Schelling hizo fue "ofrecer una nueva filosofía capaz de abordar la existencia concreta de las cosas y de fundarse no en la razón abstracta sino en la libertad como fuerza creadora y efectiva" ${ }^{11}$. El hacer a un lado la razón puede ser uno de los ecos schellingueanos que están presentes en el pensamiento de Kierkegaard, lo cual registró en las notas que tomó al asistir al curso de Berlín ${ }^{12}$. Asimismo, otro de los puntos relevantes de la Filosofía de la revelación que abonaron a comprender la existencia por la vía positiva, radicó en el hecho de que con la pura razón era imposible reconocer la existencia de una planta y menos comprender la existencia humana, porque en el caso de la planta Schelling subrayó que, si "era real, necesariamente tenía que ser en un lugar determinado del

${ }^{8}$ Friedrich Schelling, Filosofía de la Revelación, Trad. de Juan Cruz, Pamplona: Cuadernos de Anuario filosófico, 1998, p. 157.

${ }^{9}$ Villacañas, La filosofía del idealismo alemán. Vol. II, p. 299.

${ }^{10}$ Schelling, Filosofía de la revelación, p. 158.

${ }^{11}$ María Binetti, El idealismo de Kierkegaard, México: Univ. Iberoamericana, 2015, p. 65.

${ }_{12}$ Cfr. Søren Kierkegaard, Apuntes sobre la Filosofía de la Revelación de F. W. J. Schelling (1841-1842), p. 93. 
espacio y en un punto determinado del tiempo. En este caso, la razón puede reconocer por sí misma, bajo determinadas condiciones, la naturaleza de esta planta, pero jamás su ser real, actual y presente" ${ }^{13}$.

A la luz de la cita anterior, es esa dimensión de actualidad que hace tener a la existencia una condición ajena a la razón; es decir, es distinta a lo conceptual teniendo en cuenta que la razón puede revelar ideas, pero no la existencia, porque la existencia humana no es nada más un ser racional y puro al estilo kantiano. Si bien, fue este conflicto planteado por Schelling lo que hizo que su pensamiento se haya apartado del proyecto idealista y como consecuencia diera el giro hacia lo humano. Este cambio de postura inició en su obra Investigaciones filosóficas sobre la esencia de la libertad bumana, puesto que en esa obra ubicó a la libertad como parte de un sistema vivo y en su desarrollo se opuso a lo que consideró el mecanicismo racional de los sistemas anteriores, ya que para Schelling "el concepto de libertad no podía ser compatible con ningún sistema y toda filosofía que tuviera pretensiones de unidad y totalidad acaba desembocando en una negación de la libertad"14. Finalmente, el giro hacia las preocupaciones humanas culminó en su Filosofía de la revelación, lo que resonó en Kierkegaard ya que asistió a las clases del viejo Schelling. La consecuencia del encuentro de estos dos pensadores llevó a poner el acento en la parte abismática de la existencia y en temas indescifrables para la razón como la angustia.

Por otra parte, el conocimiento y la influencia de la filosofía moderna también está presente en Markus Gabriel y como experto en el idealismo alemán conoce cuáles son los tópicos que esta filosofía ha tratado, así como también el lugar que ha ocupado Schelling dentro de ella, lo anterior ha sido expuesto en dos de sus obras más densas tituladas Trascendental Ontology y Fields of Sense. Igualmente, es en la última década donde el tema de la existencia a través de Markus Gabriel ha tomado un nuevo aire en las discusiones filosóficas, ya que parte de su trabajo ha consistido en establecer un diálogo con la filosofía contemporánea que lo llevó a dar un giro epistemológico donde las experiencias subjetivas son parte de una realidad, esto se debe a que considera que tienen una consistencia ontológica y no son un epifenómeno. Es en su obra Fields of Sense donde desarrolla ampliamente el tema de la existencia sin darle mucho peso al ser humano y su postura apunta hacia un pluralismo ontológico. No obstante, tiene otras

13 Schelling, Filosofía de la revelación, p. 173.

${ }^{14}$ Friedrich Schelling, Investigaciones filosóficas sobre la esencia de la libertad bumana y los objetos con ella relacionados, trad. de Helena Cortés y Arturo Leyte, Barcelona: Anthropos, 2004, p. 110. 
obras en las que muestra el conocimiento que tiene de Kierkegaard y a la vez pone de relieve determinaciones de la existencia humana como la libertad, la voluntad y el espíritu.

\section{La categoría de la existencia en el pensamiento de Kierkegaard}

Una vez que he señalado el pensamiento de Schelling y algunos de sus aportes a la noción de la existencia en la filosofía moderna, ahora voy a ubicar de qué manera aparece en el pensamiento de Kierkegaard y cuál ha sido la importancia que ha tenido en su obra. Para desarrollar este punto tomo en cuenta la pregunta: ¿Qué es la existencia para Kierkegaard? Puedo señalar que su noción apeló al individuo; es decir, en este autor la existencia es para cada individuo algo único y al poner el acento en ese aspecto guarda distancia de las categorías dominantes de su época donde el individuo quedaba borrado por lo absoluto o, por otro lado, podría perderse en la masificación. Además, la noción de existencia kierkegaardiana está inserta en lo temporal, lo corporal, es devenir y tiene algunas pautas paradójicas que son inaccesibles para la razón.

$\mathrm{Al}$ poner el acento en el individuo y alejarlo de ser absorbido por el absoluto hegeliano, Kierkegaard inició un recorrido donde a través de sus obras mostró sus preocupaciones por la existencia humana; esto hizo que su pensamiento se haya consolidado por "no tratar con meras categorías relacionadas con el conocimiento, sino con formas existenciales; es decir, realidades en el hombre que responden a una estructura dialéctica" ${ }^{15}$. Algunas de las obras seudónimas, donde expuso el tema de la constitución dialéctica que hay en el hombre como síntesis de alma y cuerpo, fueron El concepto de la angustia y posteriormente La enfermedad mortal.

Puedo agregar que en la noción de existencia kierkegaardiana aparecen algunas vivencias de la interioridad, una de ellas es la desesperación, expuesta a través del seudónimo Anti-climacus quien señaló que la "desesperación es una categoría propia del espíritu y, en cuanto tal, guarda relación con lo eterno en el hombre"16. En la perspectiva de Anti-climacus hay quienes pueden estar distantes de ser individuos, alejarse de querer llegar a ser sí

${ }^{15}$ Luis Guerrero, Kierkegaard: Los límites de la razón en la existencia bumana, México: SIEK, 1993.

${ }^{16}$ Søren Kierkegaard, La enfermedad mortal, trad. de D. Gutiérrez Rivero, Madrid: Trotta, 2008, p. 37. 
mismos y como consecuencia no ser conscientes de lo que significa existir. Sobre esta idea no se puede dejar pasar la fórmula yoica vinculada a la conciencia y la voluntad a la que remite el seudónimo kierkegaardiano expresada de la siguiente manera: "en cuanto más consciencia, más yo, cuanta más consciencia más voluntad, cuanta más voluntad, más yo" ${ }^{17}$. El sentido de esta expresión hace referencia a la existencia desesperada en la que el yo siempre se encuentra abierto y a la vez está en constante devenir, debido a que la desesperación está considerada por Anti-Climacus bajo la categoría de conciencia. De esta manera, la repercusión característica por la falta de conciencia y voluntad en el hombre consiste en no poder tener un yo, así como también, a que no se dé la síntesis que es el espíritu.

Es también en La enfermedad mortal donde su objeción va en oposición al pensamiento sistemático de su época "por considerar que en esa filosofía no se habló para nada del hombre real e individual" ${ }^{18}$. En el apartado anterior señalé que en Schelling la filosofía racional o negativa, como él la llamó, no tomó en cuenta ese aspecto contingente que tiene la existencia humana y quiso subsumirla a lo conceptual borrando la existencia individual, dado que la filosofía y la ciencia dominante de su tiempo veía la existencia de forma general y abstracta. Sin embargo, Kierkegaard, con un estilo propio que fue expresado en sus obras seudónimas y en las que firmó como autor, puso el acento en esa situación donde se deja al individuo en un plano secundario, ya que para el pensador danés fue un terreno peligroso porque era ubicarlo al mismo nivel de la abstracción que representa la masa o la multitud. De esta manera, gran parte del trabajo del pensador danés consistió en subrayar las determinaciones de la existencia que reivindican al individuo, tal es el caso de la desesperación, la angustia, la fe y particularmente "el pecado por ser la categoría de la individualidad" ${ }^{19}$. Su interés se dio porque las explicaciones de la ciencia de su época sobre dichas determinaciones fueron insuficientes.

Una vez que he señalado algunas ideas sobre qué es la existencia y cómo se abre este horizonte en el pensamiento de Kierkegaard, el tema del individuo se ha puesto de relieve, por lo tanto, uno de sus aportes fue alejarlo de los intentos de generalizar su existencia. En esta misma dirección, Kierkegaard conoció cuáles eran los límites de la ciencia de su tiempo y en oposición sus planteamientos son un referente crítico que objetó los excesos

${ }^{17}$ Ibíd., p. 50.

${ }^{18}$ Ibíd., p. 122.

${ }^{19}$ Ibíd., p. 153. 
de los argumentos racionales modernos que en su época trataron de agotar las problemáticas y los misterios de la vida, los cuales en el pensamiento kierkegaardiano se despliegan en tres horizontes radicalmente distintos conocidos en forma de estadios o esferas; en ellos aparecen también las determinaciones existenciales y vivencias anímicas de la interioridad que he señalado en líneas anteriores como la angustia, la desesperación, la fe y el pecado.

A diferencia de la postura científica, para Kierkegaard estas vivencias no se pueden generalizar porque cada individuo las vive de manera particular, en este sentido, a través de sus planteamientos sobre la existencia "atacó el cientificismo y cualquier tentativa de erigir a la ciencia como ídolo," ${ }^{20}$ esto fue porque en la perspectiva del pensador danés era absurdo que la ciencia de su tiempo haya tratado los problemas del espíritu humano tan a la ligera; en otras palabras, como si se tratara de un simple objeto y con una postura reduccionista. Éste ha sido uno de los puntos clave donde Kierkegaard se apoyó para hacer la distinción entre la verdad subjetiva que le pertenece únicamente al individuo y la verdad objetiva de la ciencia, ya que "la verdad de la ciencia permanece neutra ante el problema de la existencia; y la verdad subjetiva, la verdad de aquello que existe, es una paradoja, porque jamás puede llegar a ser objetiva y universalmente válida" ${ }^{21}$.

Sin desviarse de los objetivos de ser un pensador de la interioridad, en su noción de existencia, Kierkegaard mostró meticulosidad para tratar el espíritu humano y cuidarlo de los excesos de la ciencia. Además, al no seguir las corrientes académicas dominantes en el reverso de su interpretación sobre la existencia se puede encontrar el tono irónico con el que varias veces cuestionó las posturas racionales de su tiempo, esto lo hizo a través de uno de sus seudónimos al manifestar que "la existencia es también una lucha y posee tanto patetismo como comicidad" 22 . En la perspectiva de Kierkegaard estos matices pasaron desapercibidos en la ciencia que trataba de explicar todo a partir de contenidos conceptuales; puede ser que hasta el día de hoy a la ciencia le siga pareciendo totalmente irracional y paradójico lo que no encuadra dentro de sus explicaciones, porque al igual que en la época de Kierkegaard, en la actualidad hay posturas que minimizan o ven a la ligera

${ }^{20}$ Francesc Torralba, "La búsqueda de Dios en Kierkegaard" en Ironía y destino. La filosofía secreta de Kierkegaard, Barcelona: Herder, 2013, p. 217.

${ }^{21}$ Arendt, "La filosofía de la existencia", p. 51.

22 Søren Kierkegaard, Postscriptum no científico y definitivo a Migajas Filosóficas, trad. de N. Bravo Jordán, México: Universidad Iberoamericana, 2008, p. 93. 
algunas situaciones del espíritu humano. Esta idea la trato con mayor detalle en el último apartado debido a que es un tema donde confluye con Gabriel.

\section{La categoría de la existencia en el pensamiento de Markus Gabriel}

Gabriel es un filósofo actual que propone una noción contemporánea de la existencia a partir de lo que él denomina una ontología de los campos de sentido, al mismo tiempo se opone a una totalidad del mundo. Asimismo, lo que caracteriza su teoría sobre la existencia es que no está terminada y en su propuesta va publicando reformulaciones. Puede contrastar que a diferencia de Kierkegaard quien centró su noción de existencia en el individuo, lo que intenta la filosofía de Gabriel es mantener un diálogo entre la filosofía continental y la analítica para tratar de superar el sesgo que hay entre ambas tradiciones, porque para Gabriel ninguna filosofía es más importante que la otra.

En su propuesta señala que "existencia es aparecer en un campo de sentido," 23 para sustentar su noción remite a la ontología de los campos de sentido y la explica en dos de sus obras, una de ellas se titula Por qué no existe el mundo y con mayor rigor filosófico lo hace en Field of Sense, debido a que en este último desarrolla a fondo los temas y argumentos sobre el tema. Al revisar estas dos obras se puede ubicar la importancia que tiene su noción de existencia porque en ambas discute su postura de los campos de sentido y en una primera definición para justificar por qué el mundo no existe como totalidad, comenta:

Los campos de sentido se dilatan en todas las direcciones imaginables, en un encapsulamiento infinito, sin que puedan establecerse de antemano las reglas por las que esa dilatación deba desarrollarse. Si hubiera alguna regla que determinara qué campo de sentido debe y de qué manera aparece como próximo, entonces existiría el mundo. El mundo, la totalidad, entonces sería la regla que lo dominara todo ${ }^{24}$.

Esta definición de campos de sentido es solamente uno de los argumentos con los que Gabriel sostiene su tesis de por qué el mundo no existe en tanto totalidad. El punto para Gabriel es que él prefiere hablar de sentidos

${ }^{23}$ Markus Gabriel, Por qué no existe el mundo, trad. de Enrique G. de la G., México: Océano, 2016, p. 83.

${ }^{24}$ Ibíd., p. 166. 
porque a partir de ellos articula una explicación con la que evade los sesgos de la metafísica y considera que son perspectivas que borran la distinción entre objetos y sentidos. Para Gabriel un precedente de la idea de sentidos se puede encontrar en el pensamiento de Frege, en su obra Por qué no existe el mundo y explica "por qué se apoyó de algunos de los presupuestos de Frege y de qué manera le ayudaron a consolidar su categoría de campos de sentido" 25 .

Una segunda definición y con mayor rigor de análisis se puede encontrar en Fields of Sense. En ella Gabriel añade a su categoría al señalar que "los campos no son horizontes o perspectivas; no son entidades epistemológicas. Son una parte esencial de cómo son las cosas y sin los campos, nada podría existir" ${ }^{26}$. De esta manera, puedo subrayar que el concepto de existencia en Gabriel se puede comprender bajo la situación de que algún objeto aparece en un campo de sentido. Ahora bien, qué son o qué pueden ser esos objetos, Gabriel explica que puede ser cualquier cosa; es decir, desde un pensamiento hasta un objeto físico, lo que implica que hay infinidad de campos que no siguen una secuencia lógica en la forma en que aparecen porque pueden venir de cualquier dirección. Por este motivo, si solamente hubiera un campo de tipo universal, entonces sería uno que todo lo abarca; no obstante, el objetivo de Gabriel apunta en señalar que esa postura no es la única.

Por otra parte, entre los diferentes tópicos que aborda en Fields of Sense lo que va a destacar es su noción de existencia y la pertinencia que tienen los campos. Adicionalmente, algo que considero pertinente para la discusión del siguiente apartado es que su propuesta sobre la existencia también se enfoca en tener "una perspectiva nueva sobre los dominios que recurrentemente tendemos a analizar como ilusiones, tales como el dominio total del espíritu humano o la subjetividad"27. De igual modo, el pluralismo ontológico de Gabriel se opone al cientificismo que intenta dar una respuesta objetiva del espíritu humano o de la misma subjetividad, por lo tanto, me detengo en la crítica que Gabriel ha hecho a los intentos de dominar el espíritu humano, particularmente en la reducción de la libertad a un proceso químico neuronal, así como también voy a señalar cómo en esta crítica hay un punto de convergencia con el pensamiento de Kierkegaard.

${ }^{25}$ Ibíd., p. 84.

${ }^{26}$ Markus Gabriel, Fields of Sense: A New Realist Ontology, Edinburgh: Edinburgh University Press, 2015, pp. 157-158.

${ }^{27}$ Ibíd., p. 38. 


\section{Kierkegaard y Markus Gabriel en la filosofía actual}

En los apartados anteriores he señalado que ambos autores objetan contra una manera de interpretar el mundo en tanto totalidad, en el caso de Kierkegaard su objeción va en contra de la metafísica de los sistemas filosóficos de su época y con una postura definida se opuso a la idea de una visión general de la existencia donde se borra y se pierde el individuo. En cambio, la postura de Gabriel va contra la metafísica en general y contra varios filósofos del siglo XX porque objeta que el mundo no existe en tanto totalidad, debido a que el mundo como campo de sentido no lo puede abarcar todo.

Al tomar en cuenta que la existencia es el tema que ambos abordan desde épocas y contextos distintos, lo anterior no ha sido un impedimento para que sus posturas se acerquen, ya que si hago un paréntesis y pongo el acento en esa convergencia puedo encontrar un diálogo para discutir el tema en la filosofía actual. En esta dirección, el interés que he tenido hacia Markus Gabriel se debe a que no ha sido ajeno al pensamiento de Kierkegaard, porque a diferencia de su obra Fields of Sense donde claramente pueden sobresalir críticas al pensamiento kierkegaardiano, en su obra Por qué el mundo no existe destacan otros matices; es decir, en ella recurre al pensador danés en distintas ocasiones para abordar un tema relacionado con el sentido de la religión.

Las menciones a Kierkegaard siguen presentes y en una obra posterior titulada Yo no soy mi cerebro, Gabriel lo vuelve a citar, aunque en esta ocasión lo deja en las breves líneas de un epígrafe que hace referencia a El concepto de la angustia. La idea que retoma señala que "ninguna época tanto como la nuestra ha tenido la gran destreza de producir mitos de inteligencia, de producir mitos cuando ella misma se propone a eliminar todos los mitos" ${ }^{28}$. No es para menos, debido a que en algunos pasajes de El concepto de la angustia a través de Vigilius Haufniensis discutió con la filosofía y la ciencia dominante de su época. Del mismo modo, al seguir la estela del pensamiento kierkegaardiano, Gabriel va a discutir las tesis del neurocentrismo con relación al tema de la libertad y en su obra Yo no soy mi cerebro aborda todo lo que supuestamente puede determinar el tema de la libertad, ya sea la sociedad, la naturaleza o los procesos neuronales del cerebro.

${ }^{28}$ Søren Kierkegaard, El concepto de la angustia. Escritos de Søren Kierkegaard. Vol. 4/2, trad. de Darío González y Óscar Parcero, Madrid: Trotta, 2016, p. 163. 
Ahora bien, en la obra Por qué el mundo no existe, Gabriel revisa el tema de Dios y la religión desde la óptica de los campos de sentido; hace una crítica a las dos perspectivas o formas de la religión. Equipara la primera a la imagen científica del mundo y expone la segunda como una forma de manifestación y asombro por lo infinito. En esta discusión Gabriel demuestra el conocimiento que tiene de Kierkegaard y lo ubica "como el primer filósofo radical de la existencia," 29 así como también expone cómo la categoría kierkegaardiana de la desesperación se relaciona con lo más propio del ser humano que es el espíritu. En consecuencia, éste va a ser uno de los puntos tratados por Gabriel para cuestionar el neurocentrismo y lo hace con mayor mesura con relación a los campos de sentido.

Gabriel se dio cuenta que, en la perspectiva del pensador danés, el espíritu es algo más que reflexión; una segunda idea que llamó su atención tiene que ver con las tres formas de desesperación que aparecen en $L a$ enfermedad mortal "donde la primera de estas formas es la del individuo que ignora tener un yo; la segunda, la del desesperado que no quiere ser sí mismo y la última es lo opuesto; es decir, la del desesperado que quiere ser sí mismo" ${ }^{30}$. En esta enfermedad que recae en el yo sobresalen también las síntesis que pueden darse en el hombre como individuo, tomando en cuenta que para Kierkegaard el yo "es una relación que se relaciona consigo misma" ${ }^{31}$. Ahora bien, esta relación del yo es una idea clave para entablar un punto de confluencia entre los dos pensadores, porque desde la perspectiva de Gabriel el espíritu humano puede ser considerado un campo de sentido, de modo que no puede ser agotado desde alguna disciplina científica, debido a que en ese campo que es propio del hombre se da una infinidad de situaciones.

En este contexto Gabriel retomó lo que Anti-climacus expuso en La enfermedad mortal y señala:

El espíritu es la circunstancia de que nos comportemos respecto con nosotros mismos como si se tratara de otro, de una persona a la que conocemos y a la que, en ocasiones, transformamos. No sólo somos sujetos del pensar, pensadores, sino ante todo, personas, y las personas se relacionan consigo mismas. En esta autorrelación tenemos plasticidad hasta cierto punto, por lo que la existencia humana es un punto vacilante ${ }^{32}$.

\footnotetext{
${ }^{29}$ Markus Gabriel, Por qué el mundo, p. 188.

${ }^{30}$ Søren Kierkegaard, La enfermedad, p. 34.

${ }^{31}$ Ibíd., p. 33.

32 Markus Gabriel, Por qué el mundo, p. 190.
} 
Esta cita destaca la oscilación que se da en la existencia que en su momento fue advertida por Schelling y Kierkegaard. En ambos pensadores la existencia además de razón tiene una dimensión espiritual donde aparece la angustia, la desesperación y la libertad. De igual forma, Gabriel sigue la estela del pensamiento de los filósofos del siglo XIX subrayando que en la existencia humana hay situaciones que se pueden cambiar, las cuales a veces, van en una dirección opuesta a la que puede llevar un ejercicio racional.

Para cerrar el presente estudio retomo lo que expuse en líneas anteriores acerca de cómo en la actualidad, desde la obra de estos dos autores, se puede cuestionar lo que propone la ciencia, particularmente una de sus variantes llamada neurocentrismo, porque desde esta disciplina se ve a la existencia, la libertad y el amor como epifenómenos. En su momento Kierkegaard objetó las interpretaciones que hizo la ciencia de su tiempo, porque para el pensador danés la existencia, la libertad y el amor tienen en cada individuo matices particulares que se presentan de manera única en ese camino que es la vida, de modo que en la perspectiva kierkegaardiana se recorre en solitario para llegar a ser sí mismo. Estas ideas no solamente apuntaron hacia la ciencia, sino también en contra del sistema hegeliano "el cual pretendía aprehender y explicar el Todo. Kierkegaard opuso el singular, el hombre individual para el cual no había lugar ni sentido en ese Todo dominado por el Espíritu del mundo" ${ }^{3}$. Frente a esto se pone de relieve la vigencia del pensamiento kierkegaardiano como precursor crítico de los intentos científicos de homogeneizar la existencia individual.

Siguiendo la referencia kierkegaardiana puedo decir que en la actualidad los temples del espíritu y sus movimientos tratan de ser explicados a partir del funcionamiento del cerebro. Está claro que en la perspectiva del pensador danés esto puede ser visto como una insensatez, lo fue en su tiempo y lo es hoy en día. Lo que hace que sus aportaciones críticas sigan estando vigentes, porque el espíritu como síntesis no puede ser explicado desde el cientificismo. Gabriel se dio cuenta de esta idea y señala que lo determinante del análisis que hizo Kierkegaard "fue su descubrimiento de que el espíritu se relaciona consigo mismo de tal manera que siempre comprendemos que es posible transformarnos a nosotros mismos" ${ }^{34}$. Desde la perspectiva de ambos autores el ser humano no está determinado y como he señalado, en Gabriel los pensamientos y las experiencias subjetivas como

${ }^{33}$ Hannah Arendt, "Filosofía de la existencia", p. 56.

${ }^{34}$ Markus Gabriel, Por qué el mundo, p. 192. 
la desesperación son parte de la realidad; es decir, existen en un campo de sentido y no son un epifenómeno porque tienen una consistencia ontológica.

Frente a la postura de una verdad universalmente valida, en su obra Yo no soy mi cerebro Gabriel hace una crítica concreta a las ciencias actuales. En ella discute las propuestas del determinismo neuronal y objeta la tesis del condicionamiento de la libertad, la voluntad y algunas otras experiencias subjetivas a partir de los procesos neuronales. En esta dirección, una de sus objeciones se enfoca en el neurocientífico alemán Wolf Stinger quien representa una postura reduccionista de lo que es el pensamiento científico, porque propone la tesis de que "nuestra voluntad y nuestra libertad están determinadas por procesos neuronales inconscientes" 35 . Esta tesis puede condensar mucho de lo que en su momento Kierkegaard cuestionó a la ciencia de su tiempo, la cual para el pensador danés "no podía explicar ciertas cosas como el pecado" 36 y se puede agregar que tampoco lo que implica la libertad.

A pesar de estas advertencias y cuestionamientos a la ciencia, hoy en día las neurociencias por la supuesta objetividad que las respalda son un referente para dar respuesta a las conductas del ser humano a partir del funcionamiento del cerebro. No obstante, el rigor y la objetividad que puedan tener no las descarta de ser cuestionadas, debido a que en la perspectiva de los campos de sentido la postura de las neurociencias es un campo más y no una postura única. Por otro lado, la noción de existencia en Kierkegaard ha sido un precedente que en la actualidad sigue abonando para comprender al individuo, ya que el espíritu del hombre se sigue cimbrando ante las dificultades que se presentan en la vida, lo cual va más allá de un proceso neuronal. Si bien, el pensador danés utilizo medios explicativos que se salían de los cánones académicos de su época; eso no fue motivo para que, a través de la ironía, lo paradójico, lo religioso, el recurso meditativo y el estilo literario haya dado un contexto sobre la existencia que incluso hoy en día sigue escapando a los reduccionismos científicos.

\section{Conclusiones}

He señalado cómo cada autor desde su contexto tiene una propuesta radical de la existencia. En el caso de Gabriel de manera muy general he

${ }_{35}^{35}$ Markus Gabriel, Yo no soy mi cerebro, p. 244.

Estudios Kierkegaardianos. Revista de filosofía 6 (2020) 
expuesto su tesis de por qué el mundo como totalidad no existe; y también de qué manera el pensamiento de Kierkegaard está presente en los márgenes de su propuesta filosófica. Otro punto que destaco es la idea que Gabriel hace de los campos de sentido, ya que al tratar de comprender la angustia desde esta perspectiva sobresale la importancia ontológica que Kierkegaard le otorgó, dado que la angustia como campo de sentido puede aparecer de varias maneras; es decir, no hay una sola forma en que aparece porque al igual que la infinitud de campos de sentido, la angustia kierkegaardiana es posibilidad infinita. Al mismo tiempo, los estadios kierkegaardianos también pueden ser vistos desde la perspectiva de los campos de sentido o incluso se anticipan a esa nueva lectura de la filosofía contemporánea, ya que la propuesta de Kierkegaard fue plantear que la existencia se abre en tres horizontes distintos y en ellos no hay mediación para pasar de uno a otro; es decir, en cada estadio se da un modo de comprender la existencia y cada uno tiene características particulares que los define.

Otro de los aspectos que he destacado es cómo ambos autores en distintas épocas se han opuesto a un modo general de existencia, como en la actualidad lo ha hecho Gabriel. Por otro lado, la postura kierkegaardiana sigue siendo un referente por oponerse a la nivelación de las determinaciones existenciales que en cada individuo se presentan de una manera particular, como sucede con la fe, la cual puede llevar a dar el salto sin mediación alguna de un estadio a otro, porque para el pensador danés es la fe lo que le permite tener una perspectiva distinta de la existencia y apelar a los imposibles de la razón. Finalmente, en la perspectiva kierkegaardiana el individuo sería una forma de destruir la idea de mundo como totalidad, porque el individuo kierkegaardiano no es el individuo cognitivo que lo determina la ciencia, sino el existencial, el que tiene la posibilidad de dar el salto al abismo.

\section{Bibliografía}

\section{Obras de Kierkegaard}

Kierkegaard, Søren, Apuntes sobre filosofía de la revelación de F. W. J. Schelling (1841-1842), trad. de Óscar Parcero, Madrid: Trotta, 2014.

El concepto de la angustia. Escritos de Søren Kierkegaard. Vol 4/2, trad. de Darío González y Óscar Parcero, Madrid: Trotta, 2016. 2008. 
Postscriptum no científico y definitivo a Migajas Filosóficas, trad. de Nassim Bravo, México: Universidad Iberoamericana, 2008.

\section{Otras obras citadas}

Arendt, Hannah, "La filosofía de la existencia", Tarea, memoria académica. No. 1, 48-68, 1968. Disponible en: http://www.memoria.fahce.unlp.edu.ar/art_revistas/ pr.1124/pr.1124.pdf

Binetti, María, El idealismo de Kierkegaard, México: Universidad Iberoamericana, 2015.

Gabriel, Markus, Fields of sense: A New Realist Ontology, Edinburgh: Edinburgh University Press, 2015.

Por qué no existe el mundo, trad. de Enrique G. de la G., México: Océano, 2016.

_— Yo no soy mi cerebro. Filosofía para la mente para el siglo XXI, trad. de Juanmari Madariaga, Barcelona: Pasado\&Presente, 2016.

- Trascendental Ontology. Essays in German Idealism, New York: Continuum, 2011.

Schelling, Friedrich, Filosofía de la revelación, trad. de Juan Cruz, Pamplona: Cuadernos de Anuario filosófico, 1998.

- Investigaciones filosóficas sobre la esencia de la libertad bumana y los objetos con ella relacionados, trad. de Helena Cortés y Arturo Leyte, Barcelona: Anthropos, 2004.

Torralba, Francesc, "La búsqueda de Dios en Kierkegaard", en Ironía y destino. La filosofía secreta de Kierkegaard, Barcelona: Herder, 2013.

Villacañas, José Luis, La filosofía del Idealismo Alemán Vol. II. La Hegemonía del pensamiento de Hegel, Madrid: Síntesis, 2001. 